\title{
NEWSBOY PROBLEM UNTUK MENYELESAIKAN MASALAH INVENTORY PROYEK NEW MODEL
}

\author{
Veronica Mailiani Sudjatmiko; K.Gita Ayu \\ Industrial Engineering Department, Faculty of Engineering, Binus University \\ Jl. K.H. Syahdan No. 9, Palmerah, Jakarta Barat 11480 \\ KGayu@binus.edu
}

\begin{abstract}
Product Quality Division is in charge to do testing and verification of motorcycle prior the order for mass production items needed. The testing is prepared by the testing department which sends the list of items needed to the warehouse to be ordered. 20 - 43\% of the items needed for testing are delayed which drives the testing department to directly order the same parts to ensure the testing is conducted on time. Crucial parts are determined through Pareto analysis and Newsboy Problem inventory model is used as the inventory system. Based on the simulation of new model project using the proposed inventory system, up to $88 \%$ of the total cost of part loss in each project can be saved.
\end{abstract}

Keywords: newsboy problem, pareto analysis, inventory

\begin{abstract}
ABSTRAK
Produk Quality Division di salah satu perusahaan automotif terbesar di Indonesia memiliki tugas untuk melakukan tes dan verifikasi sepeda motor sebelum diproduksi secara masal. Bagian ini memiliki daftar kebutuhan mengenai part sepeda motor yang digunakan untuk aktivitas testing. Daftar kebutuhan kemudian dikirimkan ke warehouse untuk pemesanan ke supplier. Kondisi saat ini, 20 - 43\% part yang digunakan untuk testing mengalami keterlambatan yang menyebabkan bagian testing melakukan direct order untuk part yang sama langsung ke supplier agar proses testing berjalan sesuai jadwal. Pareto analysis digunakan untuk menentukan part yang sering mengalami keterlambatan dan dilanjutkan dengan aplikasi newsboy problem untuk memperbaiki sistem inventory. Berdasarkan simulasi, diperkirakan penghematan biaya part yang sering mengalami keterlambatan di setiap proyek new model hingga 88\% dapat dicapai dengan adanya sistem inventory yang tepat.
\end{abstract}

Kata kunci: newsboy problem, pareto analysis, inventory 


\section{PENDAHULUAN}

PT X adalah salah satu perusahaan besar di Indonesia yang memproduksi sepeda motor. Untuk memberikan jaminan kualitas, PT X memiliki divisi Product Quality yang bertugas melakukan verifikasi kualitas terhadap produk yang dihasilkan perusahaan. Verifikasi ini tidak hanya dilakukan terhadap produk Mass-Pro Model (produk yang telah dihasilkan secara masal dan dipasarkan) tetapi juga terhadap produk new model (produk dengan tipe baru dan belum diproduksi secara masal). Verifikasi produk membutuhkan part, consumable goods serta peralatan tertentu dan pengadaan alatalat tersebut dilakukan secara sentral oleh warehouse divisi Product Quality. Permasalahan yang dihadapi oleh tim verifikasi adalah seringkali alat-alat tersebut tidak tersedia tepat waktu. Berdasarkan pengamatan, untuk part new model, rata-rata $21 \%$ hingga $43 \%$ part yang dibutuhkan per proyek (senilai 4-6 juta rupiah) mengalami keterlambatan pengiriman sedangkanleadtime pengadaan part tersebut sekitar 14 hingga 30 hari.

Berdasarkan pengamatan di bagian warehouse, beberapa kondisi yang menjadi kendala dalam pengadaan part proyek new model adalah sebagai berikut: (1) permintaan part dilakukan per proyek (tidak bersifat kontinyu), sehingga permintaan part kepada supplier dilakukan sesuai permintaan dari proyek yang akan/sedang dilaksanakan; (2) part setiap proyek memiliki spesifikasi yang berbeda, sehingga part yang sudah dipesan sebelumnya tidak dapat digunakan; (3) bagian verifikasi sering melakukan pemesanan langsung ke supplier sebagai cara untuk mengatasi keterlambatan penyediaan oleh warehouse sehingga terjadi pemesanan ganda, dan part yang dipesan oleh warehouse akhirnya tidak digunakan. Berdasarkan uraian di atas, penelitian akan difokuskan pada analisis sistem inventory yang tepat bagi pengadaan part proyek new model, termasuk model pesanan pengadaannya. Analisis sistem dilakukan berdasarkan teori-teori mengenai inventory, yang dapat digunakan untuk mendukung sistem penyimpanan dan pengadaan barang di warehouse. Tujuannya adalah untuk menurunkan tingkat keterlambatan kedatangan part proyek new model sehingga dapat mengurangi intensitas adanya pemesanan langsung dari bagian pengetesan ke supplier.

\section{METODE}

Metode awal yang dilakukan adalah mengindentifikasi permasalahan yang menjadi fokus penelitian disertai tinjauan pustaka mengenai metode yang akan digunakan.

\section{Tinjauan Pustaka}

\section{Pengertian Warehouse}

Warehouse adalah suatu tempat yang digunakan untuk menyimpan barang baik berupa raw material, barang work in process atau finished good. Dari kata warehouse maka didapatkan istilah yang berarti merupakan suatu kegiatan yang berkaitan dengan warehouse. Menurut Holy Icun Yunarto dan Martinus Getty Santika (2005) kegiatan tersebut dapat meliputi kegiatan movement (perpindahan), storage (penyimpanan) dan information transfer (transfer informasi).

\section{Sistem Manajemen Inventory}

Manajemen inventory dirancang bertujuan untuk mengontrol kegiatan inventory yang diharapkan dari pengontrolan ini adalah terjadinya pengurangan biaya-biaya yang ada di dalam warehouse, pengambilan dan pemasukan barang ke warehouse yang efektif dan efisien, serta kemudahan dan keakuratan informasi stok barang di warehouse. Sistem informasi mengenai manajemen warehouse ini sering disebut dengan warehouse management system (WMS). Menurut 
Roy L, Harmon (1993), sistem warehouse haruslah sederhana dan mudah dimengerti dengan tujuan: (1) menurunkan waktu yang dibutuhkan untuk melakukan customer service, (2) menurunkan inventory hingga tingkat terendah, serta (3) meningkatkan produktifitas dari perusahaan.

\section{Pengumpulan dan Pengolahan Data}

Untuk menghasilkan solusi yang diharapkan langkah selanjutnya adalah melakukan pengumpulan data kebutuhan dan pengadaan part new model berupa (1) database kebutuhan part (electric); (2) jumlah kebutuhan tiap part serta (3) waktu kedatangan part. data ini diperoleh dari perusahaan dan melalui wawancara langsung dengan pihak operasional dan PIC warehouce (gudang) yang berkaitan dengan aktivitas di dalam gudang. Data yang telah terkumpul kemudian diolah dengan mengklasifikasi part beserta presentase delay.

\section{Analisis}

Setelah diolah, data selanjutnya dianalisis menggunakan diagram pareto dan Newsboy Problem untuk menentukan faktor apa saja yang dapat digunakan untuk memecahkan masalah inventory part proyek new model.

\section{Analisis Pareto}

Analisis Pareto menyebutkan bahwa $80 \%$ dari masalah kualitas produksi ataupun pelayanan disebabkan oleh $20 \%$ masalah yang terjadi pada proses produksi atau proses pelayanan. Proses analisis akan lebih mudah untuk memisahkan "the vital view problem" dari "trivial many" dan kemudian mengidentifikasi masing-masing masalah yang paling mempengaruhi hasil akhir dari produksi atau pelayanan.

\section{Analisis Newsboy Problem}

Setelah dilakukan analisis Pareto untuk mengetahui part proyek new model yang sering mengalami keterlambatan, langkah berikutnya adalah menentukan analisis yang dapat digunakan untuk menghitung waktu pemesanan part agar tidak terjadi keterlambatan kedatangan part. Pemilihan analisis untuk inventory Part proyek new model dilakukan dengan membandingkan beberapa teori inventory yang dimiliki oleh beberapa ahli, antara lain teori Economic Order Quantity (EOQ), Metode Lot Size, Newsboy problem. Untuk mengetahui analisis yang digunakan untuk inventory part proyek new model, perbandingan teori inventory dapat dilihat pada Tabel 1 di bawah ini.

Tabel 1 Perbandingan Kondisi Aktual dan Metode Inventory

\begin{tabular}{clccc}
\hline No & \multicolumn{1}{c}{ Kondisi Aktual } & $\begin{array}{l}\text { Economic Order } \\
\text { Quantity (EOQ) }\end{array}$ & $\begin{array}{c}\text { Classical Lot Size } \\
\text { Model }\end{array}$ & $\begin{array}{c}\text { Newsboy } \\
\text { problem }\end{array}$ \\
\hline 1 & Demand tidak konstan & $\mathrm{X}$ & $\mathrm{X}$ & $\sqrt{ }$ \\
\hline 2 & $\begin{array}{l}\text { Part Proyek tidak dapat digunakan lagi } \\
\text { (expired) }\end{array}$ & $\mathrm{X}$ & $\mathrm{X}$ & $\sqrt{ }$ \\
\hline 3 & Tidak membutuhkan safety stock & $\mathrm{X}$ & $\mathrm{X}$ & $\sqrt{ }$ \\
\hline 4 & $\begin{array}{l}\text { Tiap part proyek memiliki spesifikasi yang } \\
\text { berbeda }\end{array}$ & $\mathrm{X}$ & $\mathrm{X}$ & $\sqrt{ }$ \\
\hline 5 & Lead Time tidak diketahui secara pasti & $\mathrm{X}$ & $\mathrm{X}$ & $\sqrt{ }$ \\
\hline
\end{tabular}

Terdapat berbagai macam teori analisis Newsboy problem, antara lain Hesham K Alvares dan Hasan A. Elmora (1994) yang menjelaskan mengenai newsboy problem: Extensions to the shortage penalty case, namun analisis ini tidak dapat diaplikasikan pada proyek ini karena dalam kasus inventory proyek new model tidak terdapat shortage penalty case. Analisis Newsboy lain yang 
mungkin dapat digunakan adalah analisis klasik Newsboy problem. Analisis klasik Newsboy problem bertujuan untuk menentukan jumlah pemesanan suatu produk untuk memaksimalkan keuntungan dalam suatu periode, serta kerangka kerja kemungkinan permintaan. Gallego dan Moon (1993) mendefinisikan bahwa Newsboy problem as the tool to decide the stock quantity of an item when there is a single purchasing opportunity before the start of the selling period, and the demand for the item is random. Classical Newsboy problem mengasumsikan jika jumlah pesanan lebih besar daripada jumlah permintaan.Tujuannya adalah untuk menentukan pertukaran barang yang optimum antara resiko overstocking untuk meminimalkan biaya yang terbuang atau untuk mengurangi keterlambatan kedatangan part. Menurut Gallego dan Moon (1993) Newsboy problem seringkali digunakan untuk menentukan keputusan sistem inventory di bidang fashion, industri olah raga, industri pakaian, di bidang manufaktur dan retail. Menurut M. Kouja (1995) Analisis klasik Newsboy problem mengasumsikan bahwa biaya per-unit adalah tetap. Diasumsikan bahwa supplier akan memberikan potongan harga jika pemesanan dilakukan lebih awal untuk mengurangi level inventory. Saat potongan harga diberikan oleh supplier dalam kurun waktu pemesanan $T$, maka pelanggan harus mempertimbangakan mengenai waktu pemesanan $t$ dan menentukan jumlah yang harus dipesan $q$. Chen dan Chuang (2001) melanjutkan analisis free distribution newsboy.

Model yang digunakan digunakan untuk menetukan kapan dan berapa banyak jumlah pemesanan yang dilakukan dalam periode tertentu. Uuntuk analisis free distribution newsboy problem terdapat beberapa parameter antara lain:

T:periode waktu untuk potongan harga

$\delta$ : potongan harga per-unit dalam jangka waktu tertentu

$\mathrm{Ct}$ : harga pembelian per-unit untuk waktu pembelian $t$

h:unit holding cost per satuan waktu

t: waktu pembelian

q: jumlah pembelian (quantity)

Menurut Chung-Chu Chuang (2001) parameter di atas dapat digunakan untuk mencari waktu yang tepat $(t)$ dalam melakukan pemesanan part proyek new model agar tidak mengalami keterlambatan dengan menggunakan rumus:

$$
\left[C t^{*} \mathrm{q}+\mathrm{h}(\mathrm{T}-\mathrm{t}) \mathrm{q}\right]-[\mathrm{Ct}-\Delta \mathrm{t} * \mathrm{q}+\mathrm{h}(\mathrm{T}-\mathrm{t}+\Delta \mathrm{t}) \mathrm{q})=(\delta-\mathrm{h}) \mathrm{q} * \mathrm{t}
$$

Jika $\delta<\mathrm{h}$, menunjukkan bahwa potongan harga yang diberikan oleh supplier tidak sesuai, prinsipnya akan kembali ke analisis klasik newsboy problem yaitu dan waktu pemesanan $(t)$ yang optimal harus dilakukan pada periode T. Persamaan di atas dapat digunakan untuk menghitung waktu yang dibutuhkan untuk melakukan pemesanan part proyek new model agar tidak mengalami keterlambatan. Hasil pengolahan data dan analisis kemudian disusun usulan pengadaan part project new model. Usulan berupa sistem pengadaan barang yang efektif agar pengadaaan part proyek new model tidak mengalami keterlambatan dan tidak terjadi order ganda Terakhir, akan ditarik kesimpulan berdasarkan tahapan penelitian yang telah dilakukan sebelumnya serta saran bagi perusahaan.

\section{HASIL DAN PEMBAHASAN}

\section{Data Inventory Part Proyek New Model}

Untuk proses analisis data inventory, digunakan data 3 proyek new model terbaru yaitu CUB1, MT3, CUB 3. Ketiga proyek new model ini berlangsung dari bulan Oktober 2010 hingga bulan Maret 2011, merupakan proyek terbaru yang di luncurkan di awal tahun 2011. Ketiga proyek new model tersebut digunakan acuan perhitungan dengan analisis Newsboy problem untuk kemudian diaplikasikan pada proyek berikutnya. Dari database inventory part elektrik untuk tiap proyek New Model, dapat disimpulkan part elektrik yang mengalami delay pada event New Model sebagai berikut (Tabel 2): 
Tabel 2 Delay Part Proyek New Model

\begin{tabular}{|c|c|c|c|c|c|c|c|}
\hline \multirow{2}{*}{ No } & \multirow{2}{*}{ Part } & \multicolumn{3}{|c|}{ Delay pada event project } & \multirow{2}{*}{ Frequency Delay } & \multirow{2}{*}{ Presentase (\%) } & \multirow{2}{*}{$\begin{array}{c}\text { Total Presentase } \\
(\%)\end{array}$} \\
\hline & & $\begin{array}{c}\text { Pre-Masspro } \\
\text { CUB1 }\end{array}$ & $\begin{array}{c}\text { Pre-masspro } \\
\text { MT1 }\end{array}$ & $\begin{array}{c}\text { Pre-masspro } \\
\text { CUB } 3 \\
\end{array}$ & & & \\
\hline 1 & AC Generator Assy & $\sqrt{ }$ & $\sqrt{ }$ & $\sqrt{ }$ & 3 & 25 & 25 \\
\hline 2 & Unit Comp CDI & $\sqrt{ }$ & $\sqrt{ }$ & $\sqrt{ }$ & 3 & 25 & 50 \\
\hline 3 & Regulator Rectifier Assy & $\sqrt{ }$ & $\sqrt{ }$ & $\sqrt{ }$ & 3 & 25 & 75 \\
\hline 4 & Speedometer Assy & $\sqrt{ }$ & $\sqrt{ }$ & & 2 & 17 & 92 \\
\hline 6 & Unit Comp PGM-FI & & & $\sqrt{ }$ & 1 & 8 & 100 \\
\hline
\end{tabular}

Sumber: pengumpulan data

Dari analisis pareto (

Gambar 1) diketahui bahwa part yang sering mengalami delay adalah AC Generator Assy, Unit Comp CDI, Regulator Rectifier Assy. Untuk itu perlu dilakukan analisis untuk ketiga part tersebut mengenai waktu pemesanan yang tepat agar tidak mengalami delay.

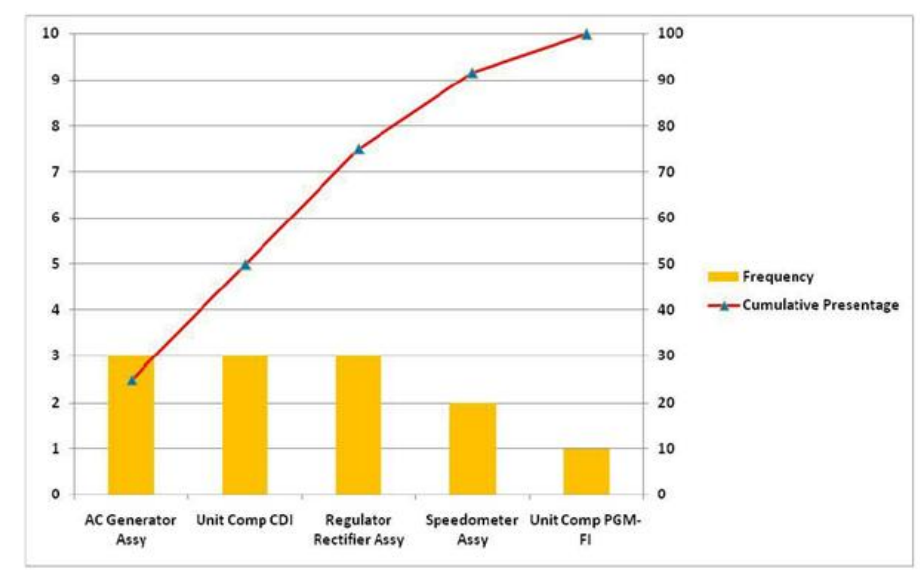

Gambar 1 Diagram pareto part new model

\section{Analisis Newsboy Problem}

Proses penghitungan dilakukan untuk part AC Generator yang memiliki presentase delay sebesar $25 \%$ dan memiliki purchasing cost paling tinggi. Parameter yang dibutuhkan untuk melakukan penghitungan waktu pemesanan adalah:

$\mathrm{C}_{\mathrm{t}} \quad$ : Harga part AC Generator dengan harga Rp. 360,000/piece

Q : Jumlah part dalam sekali pemesanan, yaitu 3 pieces

$H \quad$ : Biaya penyimpanan sebesar Rp. 2,000/hari

$\mathrm{T} \quad$ : Periode potongan harga yang diberikan oleh supplier jika pemesanan dilakukan minimal 40 hari sebelum due date

$\delta \quad$ : Potongan harga Rp. 3000/hari yang diberikan oleh supplier jika melakukan pemesanan T

Penghitungan dilakukan dengan menggunakan formula:

$$
\left[C t^{*} \mathrm{q}+\mathrm{h}(\mathrm{T}-\mathrm{t}) \mathrm{q}\right]-\left[\mathrm{Ct}-\Delta \mathrm{t}^{*} \mathrm{q}+\mathrm{h}(\mathrm{T}-\mathrm{t}+\Delta \mathrm{t}) \mathrm{q}\right)=(\delta-\mathrm{h}) \mathrm{q}^{*} \mathrm{t}
$$


Hasil perhitungan waktu pemesanan untuk partAC Generator, unit comp CDI,dan Regulator Rect Assyadalah 53, 52, dan 52 hari sebelum due date kedatangan part (karena parameter $q, h, \delta, T$ dan $h$ dari ketiga part bernilai sama dan hanya berbeda pada parameter $C_{t}$ ).

\section{Pengujian Hasil Analisis}

Pengujian dilakukan untuk membandingkan antara kondisi sebelum (Table 3) dan sesudah adanya usulan perbaikan (Tabel 4).Part yang sering mengalami keterlambatan adalah AC Generator, unit comp CDI dan regulator Rec Assy. Hasil perhitungan mengenai waktu pemesanan untuk ketiga part tersebut akan disimulasikan untuk ketiga proyek di atas yaitu CUB1, MT3, CUB 3 untuk melihat bahwa perhitungan dan analisis pemesanan dapat diaplikasikan untuk pemesanan part proyek new model berikutnya.

Tabel 3 Permintaan Part Proyek CUB1 (Sebelum Perbaikan)

\begin{tabular}{|c|c|c|c|c|c|c|c|c|c|}
\hline No & Part Name & $\begin{array}{l}\text { Total } \\
\text { Part }\end{array}$ & Date Order & Due Date & Arrived & Delay & Order & Cost & Total Cost \\
\hline \multirow{2}{*}{1} & \multirow{2}{*}{ AC Generator Assy } & 3 & 1 Oct 2010 & 3 Nov 2010 & 10 Nov 2010 & $\mathrm{v}$ & Direct \& warehouse & Rp360.000 & Rp1.080.000 \\
\hline & & 3 & 1 Oct 2010 & 3 Nov 2010 & 10 Nov 2010 & $\checkmark$ & Direct \& warehouse & Rp350.000 & Rp1.050.000 \\
\hline 2 & Regulator Rectifier & 3 & 1 Oct 2010 & 3 Nov 2010 & 11 Nov 2010 & $v$ & Direct \& warehouse & Rp180.000 & $\operatorname{Rp} 540.000$ \\
\hline 3 & Unit Comp. CDI & 3 & 1 Oct 2010 & 3 Nov 2010 & 11 Nov 2010 & $\checkmark$ & Direct \& warehouse & Rp296.000 & Rp888.000 \\
\hline \multicolumn{9}{|c|}{ Total Part Loss (Rp) } & Rp3.558.000 \\
\hline
\end{tabular}

Berdasarkan Tabel 3, pemesanan (date order) dilakukan 33 hari sebelum due date yang ditetapkan oleh bagian pengetesan.P enetapan waktu pemesanan 33 hari oleh bagian pengetesan tidak didasarkan atas perhitungan mengenai inventory, tetapi hanya berdasarkan pada pengalaman pemesanan part yang dilakukan pada proyek new model sebelumnya, yaitu pemesanan dilakukan antara 30-35 hari sebelum due date pengetesan proyek new model. Namun, kondisi aktual part yang dipesan mengalami keterlambatan $7-9$ hari dari due date. Saat part yang dipesan mengalami keterlambatan, bagian pengetesan akan melakukan pemesanan langsung ke supplier. Jika hal ini terjadi, part yang dipesan oleh melalui warehouse pada tanggal 1 Oktober tidak akan digunakan lagi, yang mengakibatkan biaya yang terbuang sebesar Rp 3.558.000. Kejadian serupa juga terulang di proyek new model berikutnya, yaitu proyek MT3 dan CUB3. Total waktu tunggu untuk part AC Generator pada proyek CUB1 adalah 40 hari. Dengan mengunakanNewsboy problem, diperoleh hasil sebagai berikut (Tabel 4):

Tabel 4 Permintaan Part Proyek CUB1 (Sesudah Perbaikan)

\begin{tabular}{|c|c|c|c|c|c|c|c|c|c|}
\hline No & Part Name & $\begin{array}{l}\text { Total } \\
\text { Part }\end{array}$ & $\begin{array}{l}\text { Date } \\
\text { Order }\end{array}$ & Due Date & Arrived & Delay & Order & Cost & Total Cost \\
\hline \multirow{2}{*}{1} & \multirow{2}{*}{ AC Generator Assy } & 3 & 12 Aug 2010 & 1 Nov 2010 & $29-0 \mathrm{kt}-10$ & $x$ & warehouse & Rp360.000 & Rp1.080.000 \\
\hline & & 3 & 12 Aug 2010 & 1 Nov 2010 & $29-0 \mathrm{kt}-10$ & $x$ & warehouse & Rp350.000 & Rp1.050.000 \\
\hline 2 & Regulator Rectifier & 3 & 12 Aug 2010 & 1 Nov 2010 & $29-0 \mathrm{kt}-10$ & $x$ & warehouse & Rp180.000 & $\mathrm{Rp} 540.000$ \\
\hline 3 & Unit Comp. CDI & 3 & 12 Aug 2010 & 1 Nov 2010 & $29-0 \mathrm{kt}-10$ & $x$ & warehouse & Rp296.000 & Rp888.000 \\
\hline \multicolumn{3}{|c|}{$\begin{array}{l}\text { Due date kedatangan } \\
\text { part }\end{array}$} & & & & & \multicolumn{3}{|c|}{ Tanggal kedatangan part } \\
\hline
\end{tabular}


Berdasarkan analisis yang dilakukan (Tabel 4) perhitungan inventory level dengan menggunakan Newsboy problem dapat diaplikasikan pada proyek new model. Dengan melakukan pemesanan part sesuai dengan waktu yang telah diperhitungkan berdasarkan analisis Newsboy, diharapkan tidak terjadi keterlambatan part untuk proyek new model, sehingga tidak ada lagi biaya yang terbuang karena adanya order ganda. Perhitungan untuk holding cost part AC Generator dengan menggunakan waktu tunggu maksimal selama 52 hari adalah:

Holding Cost $=$ holding cost $/$ hari $*$ waktu tunggu $(52$ hari -35 hari $)$

Holding Cost AC Generator $=\mathrm{Rp} 2,000 * 17$ hari

Holding Cost AC Generator $=\mathrm{Rp} 34,000$

Diperoleh hasil perhitungan holding cost untuk AC Generator pada proyek CUB1 adalah sebesar Rp. 108,000 dengan asumsi penyimpanan paling lama 52 hari, artinya pada saat pemesanan dilakukan maka part tersebut dapat langsung dikirim oleh supplierke warehouse. Jika dibandingkan antara holding cost part AC Generator dengan biaya part loss pada saat terjadi order ganda karena keterlambatan part, maka holding cost yang dikeluarkan lebih kecil.

Jika dilakukan perhitungan untuk ketiga part, total holding cost untuk ketiga part tersebut adalah Rp. 408,000 untuk sekali proyek new model. Holding cost untuk ketiga part tersebut tetap lebih rendah dibandingkan dengan biaya total loss part pada proyek CUB1 sebesar Rp 3,558,000. Dalam kasus ini, penghematan biaya yang dapat dilakukan untuk proyek CUB1 sebesar Rp 3,150,000 (87.53\%) dari total biaya part loss pada proyek CUB1. Perhitungan seperti pada proyek CUB1 dapat diaplikasikan pada proyek MT3 dan CUB3, dengan penghematan biaya sebesar $88.53 \%$.

\section{PENUTUP}

Newsboy problem dapat digunakan untuk menentukan waktu pemesanan part proyek new model. Hasil yang diperoleh adalah waktu pemesanan, yaitu 53 hari sebelum due date pengetesan unit sepeda motor serta peningkatan efisiensi pengadaan barang di warehouse dan cost saving karena tidak ada biaya yang hilang akibat order ganda. Adapun penghematan yang dapat dilakukan untuk masingmasing project CUB1, MT3 dan CUB3 adalah sebesar $87 \%$ dari total biaya loss part.

Dapat disimpulkan bahwa Newsboy problem dapat digunakan untuk menentukan waktu pemesanan tidak hanya pada elektrik part pada event proyek new model. Selain itu, analisis newsboy problem juga dapat digunakan untuk part yang lebih beragam pada event proyek new model. Penentuan waktu pemesanan dengan newsboy problem dapat diaplikasikan tidak hanya untuk part new model saja, tetapi juga untuk masspro model dengan karakteristik uncertain demand, dengan analisis lebih lanjut.

\section{DAFTAR PUSTAKA}

Chen, M.S and Chuang, C. C. (2000) An extended newsboy problem with shortage-level constraints. International Journal of Production Economics, 269-277.

Chung Chu Chuang. (2001). A distribution free newsboy problem under shortage-level constraints. Journal of the Operations Research Society of Japan. 
Gallego, G. and Moon, I. (1993) The distribution free newsboy problem: Reviews and extensions. The Journal of the Operational Research Society, 44(8), 825-834.

Harmon, Roy L. (2008). Warehouse Management System (WMS).

Logan, Nathan. (2002) Pareto analysis: when quality-control demands decision. Operations Management, 345. 